\title{
Visitantes florais de Aechmea constantinii (Mez) L. B. Sm. (Bromeliaceae) em um remanescente da Mata Atlântica do Nordeste Oriental
}

\author{
Petrúcio Alexandre Fonseca Rios ${ }^{1}$ \\ Juliana Braga da Silva ${ }^{2}$ \\ Flávia de Barros Prado Moura ${ }^{2 *}$ \\ ${ }^{1} \mathrm{PPG}$ em Agronomia, Centro de Ciências Agrárias \\ Universidade Federal de Alagoas, Maceió-AL, Brasil \\ ${ }^{2}$ PPG em Diversidade Biológica e Conservação dos Trópicos \\ Instituto de Ciências Biológicas e da Saúde, Universidade Federal de Alagoas \\ CEP 57100-000, Maceió-AL, Brasil \\ *Autor para correspondência \\ flavia.moura@pq.cnpq.br
}

Submetido em 23/04/2010

Aceito para publicação em 30/08/2010

\section{Resumo}

Este trabalho teve como objetivo principal a determinação dos visitantes florais e potenciais polinizadores de Aechmea constantinii (Mez) L. B. Sm., uma bromélia endêmica da Mata Atlântica do Nordeste Oriental do Brasil. Indivíduos reprodutivos foram acompanhados e seus visitantes florais foram registrados e determinados. Os principais visitantes florais foram: os beija-flores Glaucis hirsutus, Phaethornis ruber e Phaethornis pretrei, que efetuaram visitas legítimas pela frente das flores tocando suas partes reprodutivas. Além dos beija-flores, também se registrou visitas das abelhas Plebeia flavocincta (Hymenoptera: Apidae: Meliponini), Plebeia sp. (Hymenoptera: Apidae), Trigona spinipes (Hymenoptera: Apidae) e Euglossa cordata (Hymenoptera: Apidae: Euglossina) e das borboletas Talides sergestus (Hesperiidae: Hesperiinae) e Strymon ziba (Lycaenidae, Theclinae, Eumaeini), além de duas formiga (Hymenoptera, Formicidae), em atividade no escapo floral e nas flores da bromélia. Sugere-se que A. constantinii seja polinizada por beija-flores, uma vez que estes fazem abordagens diretas à flor, contatando as estruturas reprodutivas. A retenção de pólen no corpo das abelhas e borboletas e o contato com o estigma revelaram que estas podem exercer influência na polinização, atuando possivelmente como polinizadores secundários.

Unitermos: biologia floral, Phaethornis ruber, polinização, Trochilidae

\section{Abstract}

Floral visitors of Aechmea constantinii (Mez) L. B. Sm. (Bromeliaceae) in a remnant of the Brazilian Northeast Atlantic Rainforest. This study aims to determine the floral visitors and potential pollinators of Aechmea constantinii (Mez) L. B. Sm. (Bromeliaceae), a bromeliad endemic to the Brazilian Northeast Atlantic Rainforest. Reproductively-active individuals were observed systematically and their visitors were recorded and determined. The main recorded floral visitors were Glaucis hirsutus, Phaethornis ruber and Phaethornis pretrei (hummingbirds) which executed frontal functional floral visits in which they touched the reproductive 
parts of the flowers. Visits of Plebeia flavocincta, Plebeia sp., Trigona spinipes and Euglossa cordata (bees) and Talides sergestu and Strymon ziba (butterflies) were also recorded. In addition, two ants (Hymenoptera, Insecta, Formicidae) were identified in activity on the floral scapes and flowers of the studied bromeliad. The suggestion is made in the study that the $A$. constantinii is pollinated by hummingbirds since these birds executed direct frontal visits to the flowers, touching reproductive structures. The identification of pollen on the bodies of bees and butterflies, as well as the contact executed by visitors, with the stigma of the visited flowers, offered an indication that these species may exert an influence as secondary pollinators of Aechmea constantinii.

Key words: floral biology, Phaethornis ruber, pollination, Trochilidae

\section{Introdução}

A Floresta Atlântica brasileira é uma das 34 prioridades mundiais para a conservação (Myers et al., 2000; Mittermeier et al., 2004). Apesar de sua importância biológica restam apenas cerca $12 \%$ de sua cobertura original (Ribeiro et al., 2009). A mata alagoana está situada Região Hidrográfica do Nordeste Oriental, que abrange a floresta Atlântica situada ao norte do Rio São Francisco, entre os estados de Alagoas e Rio Grande do Norte. Este centro de endemismo é um dos mais importantes da América do Sul (Whitmore e Prance, 1987).

A Família Bromeliaceae é conhecida pela grande diversidade de espécies. Na Mata Atlântica do Nordeste Oriental, Siqueira Filho e Felix (2006) registram a presença de 87 espécies de ocorrência nos Estados de Alagoas e Pernambuco. Destas, 21 são endêmicas.

As bromélias possuem grande importância ecológica, apresentando diferentes interações e relações de interdependência com espécies da flora e da fauna (Waser e Price, 1983; Leme e Marigo, 1993; Benzing, 2000; Canela e Sazima, 2003), podendo ser consideradas fundamentais na manutenção de uma parcela significativa da diversidade biológica nos ambientes em que vivem (Martinelli, 2000; Andrade et al., 2009).

Os visitantes florais são todos os animais que visitam a flor em busca de recursos alimentares tais como pólen, néctar, ceras e outras substâncias, podendo ou não efetivar a polinização. De uma forma sucinta, a polinização efetiva depende, entre outros fatores, da adequação do formato do corpo ou de determinados órgãos do visitante floral à morfologia da flor, de como ele aborda a flor e de seu comportamento durante a sua visita (Proctor e Yeo, 1979). Diversas características morfológicas, fisiológicas e funcionais nas flores estão relacionadas à atração dos visitantes florais. O período de floração de uma espécie pode frequentemente representar uma adaptação a períodos coincidentes com os de seus visitantes específicos (Faegri e Van Der Pij1, 1979). Em adição, a cor e a forma das flores parecem contribuir como sinais visuais para os visitantes sobre o tipo de recurso que está presente em determinada espécie, oferecendo-lhe assim a possibilidade de incluí-la ou não em sua rota de forrageio (Waser e Price, 1983).

Apesar da importância ecológica da família Bromeliaceae e considerando sua grande diversidade, ainda há poucas publicações a respeito do sistema reprodutivo de suas inúmeras espécies (Martinelli, 1997; Siqueira Filho e Machado, 2001; Nara e Webber, 2002; Machado e Semir, 2006; Pereira e Quirino, 2008). Este trabalho visa responder questões relativas à interação da espécie com a fauna, durante o processo reprodutivo. Para isso, buscou-se identificar os visitantes florais e potenciais polinizadores de Aechmea constantinii. Dados complementares sobre a biologia floral são comentados, contribuindo para o conhecimento da biologia reprodutiva desta espécie endêmica da Mata Atlântica do Nordeste Oriental. As informações poderão ser usadas para manejar populações isoladas, nestes ecossistemas altamente fragmentados.

\section{Material e Métodos}

As observações de campo foram realizadas em duas etapas: julho a dezembro 2007, e maio a agosto de 2008, na mata da Serra da Saudinha $\left(09^{\circ} 22^{\prime}\right.$ 'S e $\left.35^{\circ} 43^{\prime} O\right)$. Este remanescente se caracteriza fitoecologicamente como Floresta Ombrófila Aberta e está circundada por canaviais, na porção mais externa do Município de Maceió, distante 
cerca de $20 \mathrm{~km}$ da área urbana (Assis, 2000). O material botânico testemunho foi depositado no Herbário Mac do Instituto do Meio Ambiente de Alagoas.

\section{Morfologia e biologia floral}

O estudo morfológico das flores de $A$. constantinii foi desenvolvido sobre dez indivíduos reprodutivamente ativos (com escapo floral desenvolvido), etiquetados e numerados. Foi realizado in situ o registro de informações sobre as inflorescências e suas flores, tais como, a localização (ápice, meio ou base do escapo floral), morfologia externa, cor, emissão de odor, horário e duração da antese e senescência (Silva e DominguesNeta, 2010). A receptividade do estigma foi testada a cada hora, deste a pré-antese até o fechamento das flores, com peróxido de hidrogênio $\left(\mathrm{H}_{2} \mathrm{O}_{2}\right)$ a $3 \%$ (Dafni, 1992). A coleta do néctar foi realizada com auxilio de micro-seringa graduada. Flores totalmente abertas foram coletadas $(n=6)$ e conservadas em tubos plásticos com tampa, em álcool 70\% para posterior visualização das suas peças florais com auxilio de lupa, no Laboratório de Ecologia do Museu de História Natural (MHN) da Universidade Federal de Alagoas.

\section{Visitantes florais}

As observações dos visitantes florais foram feitas de forma direta, sem uso de equipamento óptico, sobre as flores, desde o início até o final da antese. Durante os meses de floração, uma vez a cada semana, foram feitas sessões observações com duração de 12:00h (das 5:00h as 17:00h), totalizando 17 dias de observação. As sessões diárias foram encerradas somente quando se completava o fechamento das flores. Em cada sessão foram registrados os espécimes que visitavam as flores da bromélia, o horário e o número de visitas (considerando-se "visita" cada vez que o espécime se alimentava do néctar ou pólen de uma flor), o local de deposição de pólen e o comportamento dos visitantes mais frequentes. A identificação dos beija-flores foi feita através da análise de filmagens, realizadas em campo, comparada à literatura especializada (Frisch e Frisch, 2005). Insetos foram coletados com auxilio de rede entomológica, e posteriormente preparados e identificados por especialistas dos laboratórios de Entomologia da UFPE (Himenópteros), USP e UFPR (Coleópteros e Lepidópteros), onde foram depositados.

\section{Resultados e Discussão}

\section{Morfologia floral}

Aechmea constantinii possui flores inodoras e as pétalas sublinear-lanceoladas, livres, eretas com exceção do ápice, subereto na antese, formando uma corola tubular de cor vibrante, de um amarelo forte (Figura 1a). A antese iniciou-se por volta das 5:00h, estando às flores completamente abertas em torno das 5:50h. $O$ fechamento teve inicio por volta das 16:20h (Figura 1b), estando, as flores, totalmente fechadas por volta das 17:00h. Suas flores têm duração de apenas um dia, de acordo com o que tem sido relatado como padrão na subfamília Bromelioideae (Siqueira Filho e Machado, 2004).

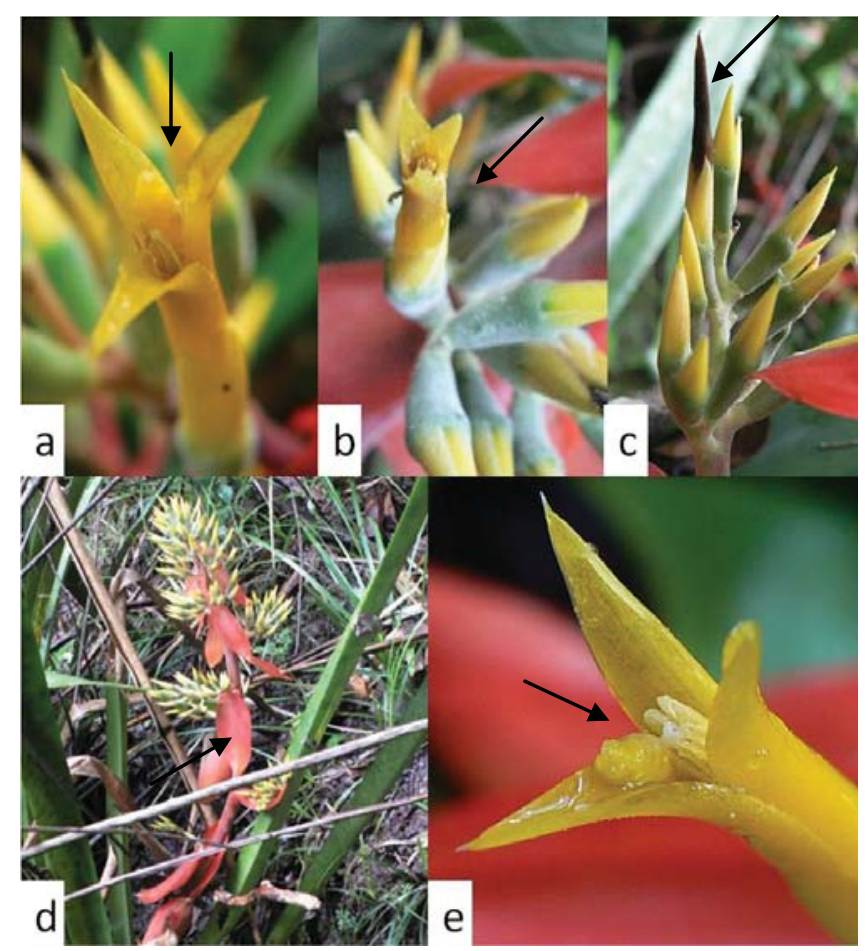

FIGURA 1: Aechmea constantinii (Mez) L. B. Sm. (Bromeliaceae): a)Flor totalmente aberta com suas pétalas sublinearlanceoladas, livres, eretas com exceção do ápice subereto durante a antese; b) Fechamento da flor, por volta das 16:20h; c) Flor, com pétalas acastanhadas após a antese; d) Escapo floral avermelhado com brácteas escapais rosa-avermelhado; e) Estigma conduplicado-espiral, elipsóide e úmido, ligeiramente excedendo as anteras. (Fotos: Rios, P. A. F.). 
As pétalas adquiriram coloração acastanhada após a antese (Figura 1c). Seu escapo floral é avermelhado com brácteas escapais rosa-avermelhado (Figura 1d).

O conjunto de características é próprio de espécies ornitófilas, porém, verifica-se alguma sobreposição de características relacionadas à melitofilia e a psicofilia, como por exemplo, tubo alongado, adaptado a probóscide comprida de alguns insetos (Machado e Lopes, 1998; Nara e Webber, 2002; Lenzi et al., 2006).

O estigma, conduplicado-espiral, elipsóide que ligeiramente excede as anteras (Figura 1e), permaneceu úmido durante todo período de antese das flores e tornou-se receptivo por volta das 6:00h, permanecendo assim durante toda a antese. A deiscência das anteras ocorreu um pouco antes do estigma tornar-se receptivo, caracterizando assim uma breve dicogamia protândrica. Esta estratégia evita o contato do pólen com o estigma no momento da abertura da antera, diminuindo as probabilidades de que venha ocorrer a autopolinização. A dicogamia, segundo Martinelli (1997), é comum à maioria das espécies de Bromeliaceae.

O néctar é produzido e armazenado na base do tubo da corola. A maior quantidade de néctar foi registrada das 5:20h as 7:20h $(19,5 \mu \mathrm{l}$. e $31,7 \mu \mathrm{l}$, respectivamente). A partir de então a produção começa a cair progressivamente. Após o final da manhã o volume do néctar não foi suficiente para ser calculado. Todos os visitantes florais foram registrados durante o período da manhã, quando havia produção de néctar. Embora as observações tenham se entendido até as 17:00h e a receptividade do estigma tenha sido mantida durante todo período de antese, não foram registrados visitantes florais após as 12:00h.

\section{Visitantes florais e potenciais poliniza- dores}

Em 204 horas de observação, as flores de Aechmea constantinii foram visitadas por nove espécies: três beijaflores, quatro abelhas e duas borboletas, forragearam néctar ou pólen. Os beija-flores foram: Glaucis hirsutus (Gmelin, 1788) (Trochilidae: Phaethornithinae), Phaethornis ruber (Linnaeus, 1758) (Trochilidae: Phaethornithinae) e Phaethornis pretrei (Lesson e Delattre, 1839) (Trochilidae: Phaethornithinae). Segundo Nara e Webber (2002), os Phaethorninae parecem constituir o principal grupo de beija-flores polinizadores de Bromeliaceae.

Geralmente, após as visitas dos beija-flores a abertura da corola aumentou, expondo ainda mais o estigma. O estilete permaneceu ereto ou foi deslocado para um dos lados, fenômeno também constatado por Siqueira Filho e Machado (2001) em Canistrum aurantiacum (Bromeliaceae).

As abelhas visitantes foram: Plebeia flavocincta (Cockerell, 1912) (Hymenoptera: Apidae: Meliponini), Plebeia sp. (Hymenoptera: Apidae), Trigona spinipes (Fabricius, 1793) (Hymenoptera: Apidae) e Euglossa cordata (Linnaeus, 1758) (Hymenoptera: Apidae: Euglossina). As borboletas registradas visitando as flores da bromélia foram: Talides sergestus (Cramer, 1775) (Hesperiidae: Hesperiinae) e Strymon ziba (Hewitson, 1868) (Lycaenidae, Theclinae, Eumaeini).

A maioria das espécies de bromélias está relacionada à ornitofilia em especial aos beija-flores (Siqueira Filho e Machado, 1998; Canela e Sazima, 2003). Por outro lado, os insetos são responsáveis pela polinização da maioria das plantas tropicais (Bawa et al., 1985) e a entomofilia, apesar de pouco constatada na família Bromeliaceae, tem sido considerada uma estratégia de polinização intermediária, e em muitos casos, funcional (Benzing, 2000).

\section{Comportamento dos visitantes florais}

A espécie de beija-flor Glaucis hirsutus foi observada forrageando e inspecionando as flores de A. constantinii, com abordagem direta à flor; seu bico tocou os verticilos reprodutivos das flores, no período das 6:00h até próximo às 12:00h, efetuando em média, cinco visitas a cada hora, abordando, em cada uma de suas visitas, mais de uma flor e vários indivíduos. Adotou estratégia territorialista, permanecendo próxima a área onde havia plantas floridas. Apesar desse comportamento não foi registrada nenhuma interação agonística interespecífica.

O fato de $P$. ruber e $P$. pretrei não terem permanecido próximo às flores da bromélia, sugere que estas aves 
apresentam técnica de forrageamento do tipo "linha de captura", ou seja, efetuam um longo roteiro de visitas, não demarcando território definido. Para estas duas espécies a frequência de visitas foi menor (2 a 3 visitas a cada hora, no período das $6: 00 \mathrm{~h}$ até próximo às 12:00h). Segundo Tonhasca Junior (2005), o interior da floresta é o hábitat desses beija-flores conhecidos como "limpa-casa" ou "eremita", não territoriais e que forrageiam em áreas relativamente extensas. Esta estratégia de forrageamento é típica das espécies da subfamília Phaetorninae (Gottsberger, 1986).

Todas as espécies de beija-flores efetuaram visitas legítimas pela frente tocando as partes reprodutivas das flores, não tendo sido observadas tentativas de perfuração da base da flor para pilhagem de néctar.
Dada à estrutura das flores da bromélia, nas quais as anteras ocorrem no interior da corola tubulosa, o bico dos beija-flores tendeu a ser o local mais frequente de impregnação de pólen. Fato também observado por Machado e Semir (2006) em 14 espécies de bromélias visitadas por beija-flores no sudeste do país. A limpeza do bico e partes do corpo dos beija-flores foi registrada no momento em que estes animais se encontravam em descanso em galhos próximos as populações de bromélias. Isso se deu, principalmente, para o beija flor que apresentou comportamento territorialista ( $G$. hirsutus).

As abelhas visitantes, Plebeia flavocincta (Figura 2a), Plebeia sp. (Figura 2b) e Trigona spinipes, apresentaram comportamento de forrageio semelhante

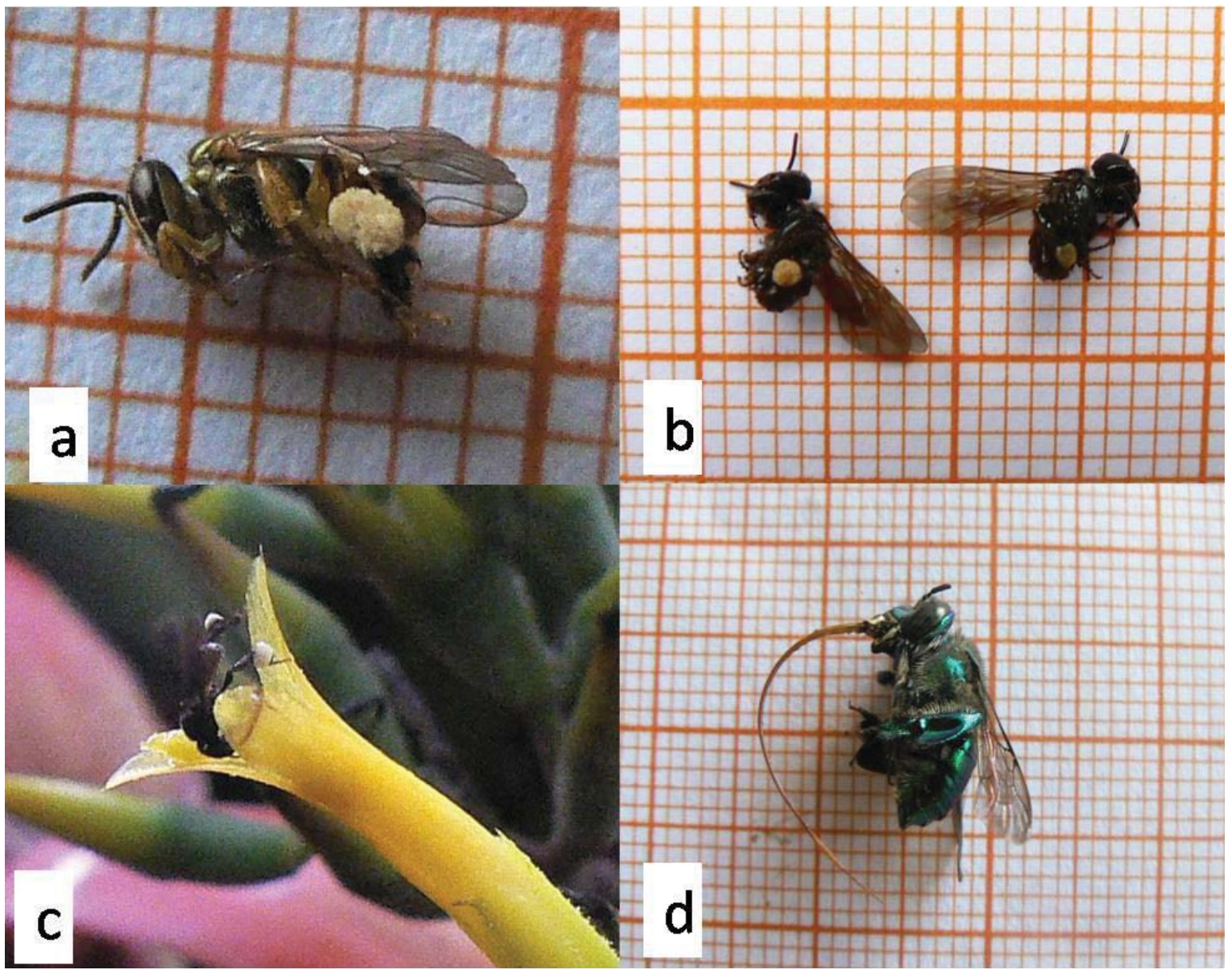

FIGURA 2: Material coletado em Aechmea constantinii (Mez) L. B. Sm., (Bromeliaceae): a) Espécime de Plebeia flavocincta (Cockerell, 1912) (Hymenoptera: Apidae: Meliponini), notar massa de pólen aderida à pata posterior da abelha; b) Espécime de Plebeia sp. (Hymenoptera: Apidae); c) Espécime de Plebeia sp. pilhando pólen, na flor de Aechmea constantinii (Mez) L. B. Sm., (Bromeliaceae), notar massa de pólen acumulada nas corbículas presentes nas patas posteriores da abelha; d) Espécime de Euglossa cordata (Linnaeus, 1758) (Hymenoptera: Apidae: Euglossina), notar sua glossa, língua comprida que facilita a coleta de néctar. (Fotos: Rios, P.A.F.). 
entre elas, e iniciaram em geral suas atividades por volta das 5:00 h., permanecendo até por volta das 11:00h, sobrepondo o horário de visitas dos beija-flores. A frequência de visitas foi alta, variando em torno de 10 visitas por hora para cada espécie de abelha. Não foi constatada, em nenhuma das espécies de abelhas, tentativas de pilhar néctar perfurando a base da corola pela face externa. Nas flores que apresentaram o escapo floral em posição horizontal as abelhas chegavam próximo às flores utilizando as pétalas como "pista de pouso", caminhando até os estames para coletarem o pólen ativamente. Nas flores em posição vertical as abelhas pousavam inicialmente nas pontas das pétalas (Figura 2c), posteriormente apoiavam-se sobre o estigma introduziam a cabeça e o primeiro par de pernas dentro da corola e começavam a coletar pólen; durante a transferência deste para as pernas medianas e destas para a corbícula no último par de pernas, grãos de pólen podem ficar aderidos ao estigma rico em substâncias mucilaginosas. Podendo assim, estas abelhas atuarem como eventuais polinizadores da bromélia.

As abelhas da espécie Euglossa cordata (Figura 2d) começavam suas atividades por volta das 6:00h, encerrando-se às 10:00h. Estas abelhas aproximavamse frontalmente das flores e antes de pousarem, as pétalas serviam de pista de pouso, geralmente girava em volta da flor como em reconhecimento, pousavam e introduziam sua glossa nas flores tubulares de $A$. constantinii, apoiando-se, principalmente, com suas pernas protóracicas.

Devido ao seu aparato bucal, com glossa, é possível coletar néctar das flores tubulosas não sendo observada tentativa de perfuração da corola da flor.

Abelhas são polinizadores de algumas espécies da subfamília Bromelioideae (Araújo et al., 2004) e provavelmente de algumas da subfamília Pitcairnioideae (Varadarajan e Brown, 1988). Durante as observações realizadas no presente trabalho, as abelhas transferiram os grãos de pólen pilhado e aderido ao corpo, para as corbicolas antes de abordarem outro indivíduo da Bromélia. Desta forma, apesar da alta frequência de visitas, as abelhas foram classificadas como polinizadores secundários.

Para as espécies de borboleta foram registradas apenas visitas eventuais. O espécime de Talides sergestus (Figura 3a) foi registrado coletando néctar das flores de A. constantinii por volta das 6:00h. Pousou apoiando-se na corola tubular da flor; introduziu sua probóscide entre as pétalas livres, atingindo assim a câmara nectarífera (com nectários ocultos) localizada na base da flor. No momento em que sua probóscide é esticada, esta pode entrar em contado com as anteras, alojadas no interior da flor, neste momento grãos de pólen podem aderir à estrutura bucal do visitante. Já o indivíduo de Strymon ziba (Figura 3b) foi observado em atividade

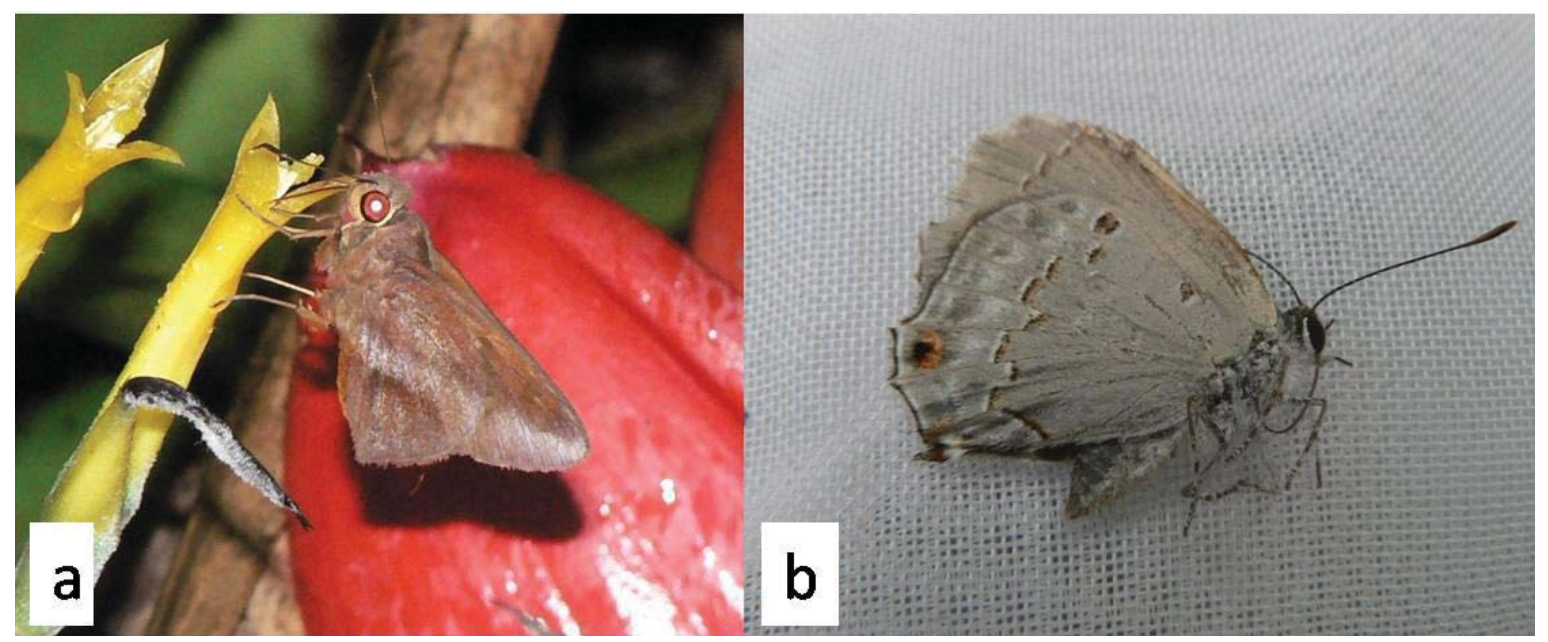

FIGURA 3: Borboletas visitantes de Aechmea constantinii: a) Espécime de Talides sergestus (Cramer, 1775) (Hesperiidae: Hesperiinae) na flor, notar probóscide introduzida na corola tubular; b) Strymon ziba (Hewitson, 1868) (Lycaenidae, Theclinae, Eumaeini), coletado em Aechmea constantinii (Mez) L. B. Sm., (Bromeliaceae), no município de Maceió, Estado de Alagoas. (Fotos: Rios, P.A.F.). 
nas flores da bromélia por volta das 10:00h, também foi constatada aderência de grãos de pólen à estrutura bucal dos espécimes. Além da visitas de cada uma das borboletas ter sido observada uma única vez, estas não foram em mais de uma flor, impossibilitando, dessa forma, a transferência do grão de pólen que por ventura tenha aderido ao seu corpo.

Segundo Benzing (2000), em Bromeliaceae insetos são polinizadores menos comuns e, quanto ocorre, a polinização é realizada por abelhas ou borboletas. As bromélias polinizadas por borboletas apresentam características semelhantes das polinizadas por abelhas. A Psicofilia não é muito comum em Bromeliaceae, mas Siqueira Filho e Machado (1998) relataram a ocorrência de polinização por borboletas em uma espécie de Hohenbergia (Bromelioideae) e Varassin e Sazima (2000) em outras sete espécies de bromélias, gêneros: Acanthostachys Klotzch, Aechmea, Billbergia Thunb. (Bromelioideae), Tillandsia L. e Vriesea (Tillandsioideae).

\section{Interações adicionais}

Além dos visitantes florais, indivíduos pertencentes a duas espécies de formigas (Hymenoptera, Insecta, Formicidae) foram registradas em atividade no escapo floral da bromélia. Os indivíduos da espécie 1 - Odontomachus haematodus (Linnaeus, 1758) (Figura 4a) mantiveram-se ativos, percorrendo toda extensão do escapo floral durante todo período com luz; transportando pulgões (Homóptera, Aphididae) para regiões superiores do escapo, local mais próximo às flores e talvez de melhor acesso aos vasos condutores de seiva da planta pelos pulgões (Figura 4b). Associações com homópteros e formigas da espécie $O$. haematodus não é muito comum de acordo com Delabie (2001), uma vez que a associação entre formigas e hemípteros é típica de formigas filogeneticamente mais avançadas.

A segunda espécie de formiga não teve sua determinação taxonômica (Figura 4c). Seus indivíduos foram registrados coletando néctar em flores previamente isoladas, para verificação do volume de néctar produzido durante a antese. Há registros de fortes relações mutualistas entre formigas coletoras de néctar extrafloral e bromélias, mas em $A$. constantinii a câmara nectarífica fica situada acima do ovário, dentro da flor. Desta forma este comportamento pode ser classificado como oportunista, e explicado talvez pelo fácil acesso ao néctar que extravasou por entre as pétalas livres da flor.

De acordo com as características florais, $A$. constantinii é uma bromélia ornitófila, com características que também podem ser associadas à psicofilia. A abertura das anteras, antes de o estigma se tornar receptivo, pode impedir o contato entre anteras e estigma nos primeiros momentos de antese, dificultando a autopolinização. Sugere-se que A. constantinii seja polinizada por beijaflores, uma vez que estes fazem abordagem direta á flor, contatando as estruturas reprodutivas caracterizando visita legítima. A retenção de pólen no corpo das abelhas e borboletas e o contato destas com o estigma indicam que estes animais podem exercer influência eventual na polinização.

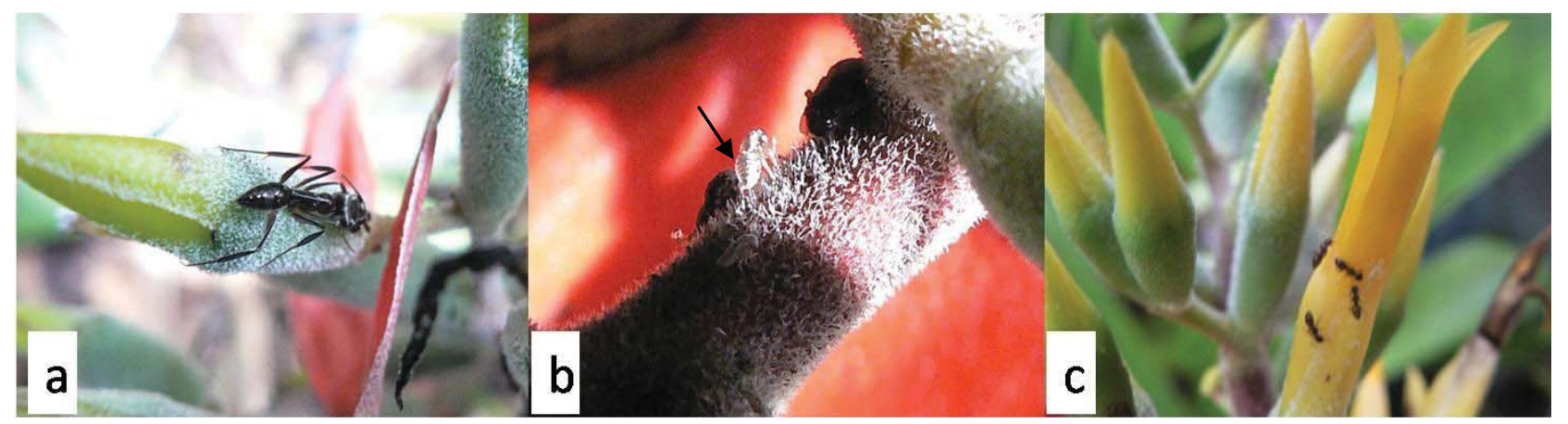

FIGURA 4: Formigas e Pulgões: a) Odontomachus haematodus Linnaeus, 1758, (Hymenoptera, Formicidae) em atividade no escapo floral de Aechmea constantinii (Mez) L. B. Sm., 1970, (Bromeliaceae); b) Pulgão (Hemiptera, Aphididae) no escapo floral de A. constantinii; c) Formiga sp. 2 (Hymenoptera, Formicidae) em comportamento oportunista, coletando néctar, que escorreu por entre as pétalas da flor de A. constantinii. (Fotos: Rios, P.A.F.). 


\section{Agradecimentos}

Os autores agradecem ao CNPq e FAPEAL, pela concessão das duas bolsas PIBIC para o primeiro e segundo autor, ao MHN-UFAL pelo apoio nos laboratórios de pesquisa, ao Grupo Carlos Lyra, pelo transporte e alojamento dos pesquisadores na área de estudo.

\section{Referências}

Andrade, E. V. E.; Albertim, K. M.; Moura, G. J. B. 2009. Primeiro registro do uso de Bromeliaceae por Elachistocleis ovalis (Schneider, 1799) (Anura: icrohylidae). Biota Neotropica, 9 (4): versão eletrônica.

Araújo, A. C.; Fischer, E.; Sazima, M. 2004. As bromélias na região do Rio Verde. In: Marques, O. A. V. \& Duleba, W. (Ed.). Estação Ecológica Juréia-Itatins: ambiente físico, flora e fauna. Editora Holos, Ribeirão Preto, Brasil, 384pp.

Assis, J. S. 2000. Biogeografia e conservação da biodiversidade: projeções para Alagoas. Edições Catavento, Maceió, Brasil, 200pp. Bawa, K. S.; Bullock, S. H.; Perry, D. R.; Coville R. E.; Grayum, M. H. 1985. Reproductive biology of tropical lowland rainforest trees: II. Pollination systems. American Journal of Botany, 72: 346-356.

Benzing, D. H. 2000. Bromeliaceae: profile an adaptive radiation. Cambridge University Press, Cambridge, UK, 690pp.

Canela, M. B. F.; Sazima, M. 2003. Aechmea pectinata: a hummingbirddependent bromeliad with inconspicuous flowers from the rainforest in south-eastern Brazil. Annals of Botany, 92: 731-737.

Delabie, J. H. C. 2001. Trophobiosis between Formicidae and Hemiptera (Sternorrhyncha and Auchenorrhyncha): an overview. Neotropical Entomology, 30 (4): 501-516.

Dafni, A. 1992. Polinização ecology: a practical approach. Oxford University Press. New York, USA, 250pp.

Faegri, K.; Van Der Pijl, L. 1979. The principles of pollination ecology. Pergamon Press, Oxford, UK, 244pp.

Frisch, J. A.; Frisch, C. D. 2005. Aves brasileiras e plantas que as atraem. $3^{\text {a }}$ ed. Dalgas Ecoltec - Ecologia Técnica Ltda., São Paulo, Brasil, 480pp.

Gottsberger, G. 1986. Some pollination strategies in neotropical savannas and forests. Plant Systematic Evolution, 152: 29-45

Lenzi, M.; Zarur, Z. M.; Orth, A. I. 2006. Variação morfológica e reprodutiva de Aechmea lindenii (E. Morren). Acta Botanica Brasilica, 20 (2): 487-500.

Leme, E. M. C.; Marigo, L. C. 1993. Bromélias na natureza. Marigo Comunicações Visual, Rio de Janeiro, Brasil, 183pp.

Machado, C. G.; Semir, J. 2006. Fenologia da floração e biologia floral de bromeliáceas ornitófilas de uma área da Mata Atlântica do Sudeste brasileiro. Revista Brasileira de Botânica, 29 (1): 163-174.

Machado, I. C.; Lopes, A. V. 1998. A polinização biótica e seus mecanismos na Reserva Ecológica de Dois Irmãos. In: In: Machado, I. C.; Lopes, A. V. \& Porto, K. C. (Orgs). Reserva ecológica de Dois Irmãos: estudos em um remanescente de Mata Atlântica em área urbana (Recife - Pernambuco - Brasil). Ed. Universitária da UFPE, Recife, Brasil, p.173-195.

Martinelli, G. 1997. Biologia reprodutiva de Bromeliaceae na Reserva Ecológica de Macaé de Cima. In: Lima, H. C. de \& Guedes-
Bruni, R. R. (Eds). Serra de Macaé de Cima: diversidade florística e conservação em Mata Atlântica. Jardim Botânico do Rio de Janeiro, Rio de Janeiro, Brasil, p.213-250.

Martinelli, G. 2000. The bromeliads of the Atlantic Forest. Scientific American, 282 (3): 86-93.

Mittermeier, R. A.; Gil, P. R.; Hoffmann, M.; Pilgrim, J. B. T.; Mittermeier, C. G.; Lamoreux, J.; Fonseca, G. A. B. 2004. Hotspots revisited: earth's biologically richest and most endangered ecoregions. CEMEX, Mexico City, Mexico, 433pp.

Myers, N. R. A.; Mittermeier, C. G.; Mittermeier, G. A. B. F.; Kents, J. 2000. Biodiversity hotspots for conservation priorities. Nature, 403: 853-858.

Nara, A. K.; Webber, A. C. 2002. Biologia floral e polinização de Aechmea beeriana (Bromeliaceae) em vegetação de baixio na Amazônia Central. Acta Amazônica, 32 (4): 571-588.

Pereira, F. R. de L.; Quirino, Z. G. M. 2008. Fenologia e biologia floral de Neoglaziovia variegata (Bromeliaceae) na caatinga paraibana. Rodriguésia, 59 (4): 835-844.

Proctor, M.; Yeo, P. 1979. The pollination of flowers. Ed. Collins ST James's Place, London, UK, 382pp.

Ribeiro, M. C.; Metzger, J. P.; Martensen, A. C.; Ponzozi, F.; Hirota, M. 2009. Brazilian Atlantic Forest: how much is left and how is the remaining forest distributed? Implications for Conservation. Biological Conservation, 142: 1141-1153.

Silva, C. A.; Domingues Neta, A. M. 2010. Aspectos reprodutivos e visitantes florais de Duguetia marcgraviana Mart. (Annonaceae) na região sudoeste de Mato Grosso. Biotemas, 23 (1): 69-76.

Siqueira Filho, J. A.; Felix, L. P. 2006. Bromélias e Orquídeas. In: Porto, K. C.; Tabarelli, M. \& Almeida-Cortez, J. S. (Org.). Diversidade biológica e conservação da floresta Atlântica ao norte do Rio São Francisco. Ministério do Meio Ambiente, Brasília, Brasil, p.219-226.

Siqueira Filho, J. A. de; Machado, I. C. S. 1998. Foral biology of Hohenbergia ridleyi (Baker) Mez. Bromelia, 5 (1-4): 3-13.

Siqueira Filho, J. A. de; Machado, I. C. S. 2001. Biologia reprodutiva de Canistrum aurantiacum E. Morren (Bromeliaceae) em remanescente da Floresta Atlântica, Nordeste do Brasil. Acta Botanica Brasilica, 15 (3): 427-443.

Siqueira Filho, J. A. de; Machado, I. C. S. 2004. Síndromes de polinização de uma comunidade de Bromeliaceae e biologia floral de Vriesea psittacina (Hooker) Lindley (Bromeliaceae) em Brejos dos Cavalos, Caruaru, Pernambuco. In: Porto, K. C.; Cabral, J. J. P.; Tabarelli, M. (Org.). Brejos de altitude em Pernambuco e Paraíba: história natural, ecologia e conservação. Ministério do Meio Ambiente, Brasília, Brasil, p. 277-284.

Tonhasca Junior, A. 2005. Ecologia e história natural da Mata Atlântica. Ed. Interciência Ltda, Rio de Janeiro, Brasil, 198p.

Varadarajan, G. S.; Brown, G. K. 1988. Morphological variation of some floral features of the subfamily Pitcairnioideae (Bromeliaceae) and their significance in pollination biology. Botanical Gazzete, 149: 82-91.

Varassin, I. G.; Sazima, M. 2000. Recursos de Bromeliaceae utilizados por beija-flores e borboletas em Mata Atlântica no Sudeste do Brasil. Boletim do Museu de Biologia Mello Leitão, 11/12: 57-70.

Waser, N. M.; Price, M. V. 1983. Pollinator behavior and natural selection for flower colour in Delphinium nelsonii. Nature, 302: 422-424.

Whitmore, T. C.; Prance, G. T. 1987. Biogeography and quaternary history in Tropical America. Clarendon Press, Oxford, UK, 224 pp. 